\title{
Severiano Porto: lições para as cidades amazônicas
}

\author{
Marcos Paulo Cereto ${ }^{1}$ \\ 1 Mestre em Arquitetura pelo PROPAR/UFRGS. Universidade Federal do Amazonas, Brasil. E-mail: mcereto@hotmail.com
}

\begin{abstract}
RESUM 0: Este ensaio é um recorte da pesquisa "Severiano Porto e a Arquitetura M oderna na Amazônia" e algumas reflexões apresentadas na conferência ministrada no I Congresso de Arquitetura e Urbanismo no Meio do M undo, realizado em setembro de 2015 em Macapá. Destaca os precedentes modernos na construção do pensamento do arquiteto Severiano Porto. Em 36 anos de atividades na Amazônia, Severiano Porto realizou mais de 300 projetos e foi premiado diversas vezes pelo Instituto de Arquitetos do Brasil, nas décadas de 70 e 80 . A visão particular da sua obra com o diálogo desejado entre a universalidade e a cultura local representou um caminho possível para as cidades amazônicas. Permite refletir o papel do arquiteto na Modernidade Amazônica e a sua contribuição para a qualificação da arquitetura produzida na atualidade. Navegando pela a permanência e o transitório, entre o universal e o regional, Severiano Porto é atemporal e merece a reverência como um importante arquiteto moderno na história da arquitetura brasileira.
\end{abstract}

Palavras-chave: Arquitetura M oderna; Severiano Porto; Amazônia.

Severiano Porto: Lessons for Amazon cities

ABSTRACT: This essay is part of a research "Severiano Porto and Modern Architecture in the Amazon" and some thoughts on the conference given at the First Congress of Architecture and Urbanism in the World Environment, happened on September 2015 in Macapa. Highlights the modern precedent in the construction of the thought of Severiano Porto architect. In 36 years of activities in the Amazon, Severiano Porto completed over 300 projects and has been awarded several times by the IAB - Instituto de Arquitetos do Brasil, in the 70 and 80 decades. The particular vision of his work with the desired dialogue between universality and local culture was a possible way to the Amazon cities. Lets reflect the architect's role in the Amazon Modernity and its contribution to the qualification of architecture produced today. Browsing the permanence and the transition between the universal and regional, Severiano Porto is timeless and deserves reverence as an important modern architect in the history of Brazilian architecture.

Keywords: Modern Architecture; Severiano Porto; Amazon.

\section{PROCESSO DE URBANIZAÇÃO DA AMAZÔNIA}

A discussão sobre as cidades amazônicas na contemporaneidade proposta pelo primeiro Congresso de Arquitetura e Urbanismo no M eio do M undo, e, no caso específico desse ensaio, sobre a produção arquitetônica nas cidades amazônicas, nos remete a um problema comum na arquitetura contemporânea: 0 diálogo entre as diretrizes, sistemas formais e métodos universais em contraponto (ou em conjunto) com à identidade cultural. É possível produzir arquitetura de qualidade na Amazônia? 
A generalização do termo "cidades" em razão da escala da Amazônia não é adequada. Saint-Clair Trindade demonstrou em sua conferência nesse congresso, que há uma diversidade de cidades na região amazônica que poderiam ser categorizadas em distintos tipos para implantarmos políticas públicas adequadas a cada categoria. Assim para as políticas públicas como também para a arquitetura, onde não podemos desconsiderar as diferenças entre as diversas regiões, escala e características das cidades amazônicas.

Segundo 0 arqueólogo Eduardo Góes Neves, as cidades pré-colombianas amazônicas surgiram há pelo menos 14 mil anos e apresentavam uma alta densidade populacional em contraponto à ideia vigente da floresta intocada e virgem. Haviam cerca de 20 milhões de habitantes na Amazônia que desenvolviam o cultivo da terra preta e da cerâmica e representavam uma forma de convívio harmonioso com o meio. Os indígenas ocuparam e construíram cidades na Amazônia com a visão de pertencimento do ser humano à floresta e ao seu meio ao contrário do modelo europeu que demonstrava o interesse pela apropriação da terra, da exploração imediatista e uma menor capacidade de diálogo e de equilíbrio.

Durante o período colonial, os portugueses e os espanhóis implantaram um modelo de ocupação no Brasil com o objetivo da exploração dos recursos disponíveis para a comercialização sem considerar um planejamento adequado. Esse modelo mercantilista não considerou a sabedoria e a tradição indígena na relação com as matas e as florestas, vista como selvagem, bárbara e inadequada aos ideais do homem renascentista. Implantar modelos aceitos pela sociedade que ali se instalaria possibilitava retratar uma realidade urbana similar ao local de origem e garantir aos imigrantes e colonizadores uma aproximação maior aos seus valores e a sua cultura. Assim na África, no Brasil e também na Amazônia.

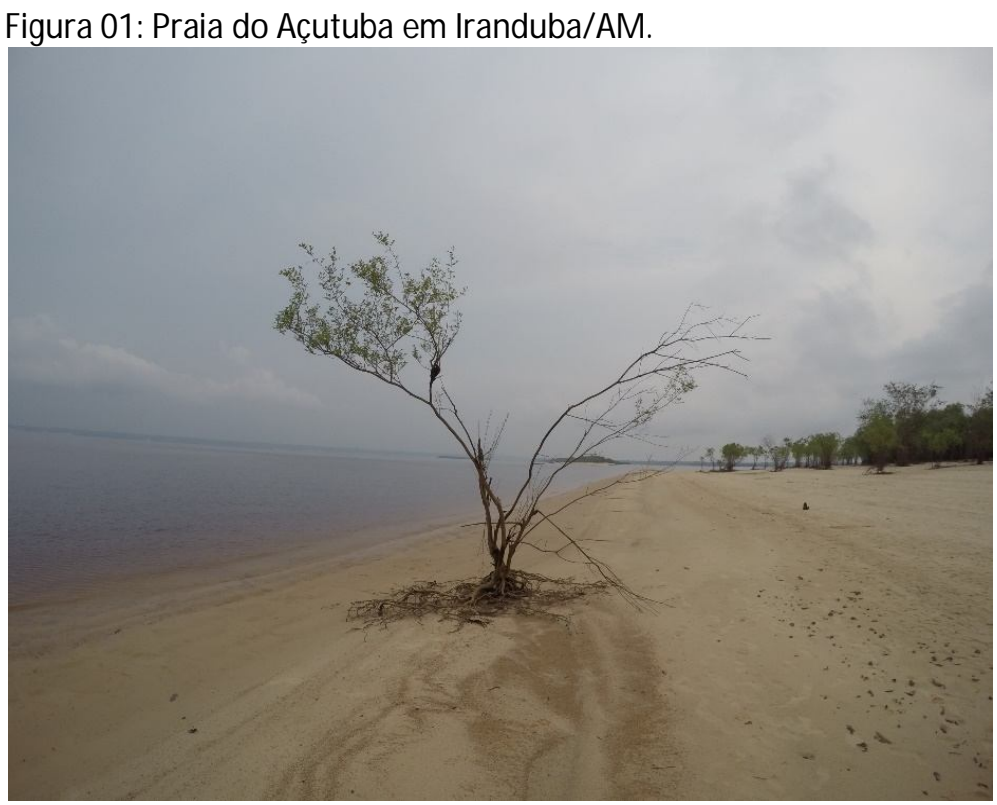

Fonte: Autor, 2015. 
Com a mudança da capital federal para o Rio de Janeiro em 1763 para um controle maior da exploração do ouro e depois com a chegada da Família Real ao Brasil em 1808, as cidades amazônicas ficaram mais distantes e a margem do desenvolvimento. A implantação das vilas, vilarejos e cidades pela corte ocorreu de forma inicial no litoral brasileiro, no período colonial e foram importados os estilos arquitetônicos do Renascimento, Maneirismo, Barroco, e Neoclassicismo com o crescente cuidado nos quatro séculos com a adequação climática. $A$ adoção de beirais, muxarabis e amplas ventilações representaram a preocupação com o clima nas cidades brasileiras. Cabe destacar a importante contribuição do Antônio Francisco Lisboa, o "Aleijadinho" nas vilas mineiras e do arquiteto italiano Antonio José Landi na província do Grão-Pará na concepção dos seus edifícios.

No ciclo da borracha, com o desenvolvimento em marcha nas cidades da região amazônica, Manaus, Porto Velho e Belém tornaram-se cidades importantes no cenário da recente república brasileira, com avanços urbanísticos significativos. 0 látex representava $40 \%$ dos produtos exportados na balança comercial. As cidades tiveram planos traçados em malha xadrez e não consideraram a Geografia da região, rica em cursos d'água. A arquitetura estilística da Belle Époque representou avanços na adaptação do edifício ao seu meio e uma significativa sofisticação na utilização de técnicas, meios e materiais que as distinguiam das demais cidades no cenário nacional. Os ingleses desenvolveram edifícios adequados ao meio tropical, tanto na Índia como no Brasil, além de técnicas construtivas que permitiram a construção mista com elementos industrializados e locais, manipulados pelos construtores amazônicos.

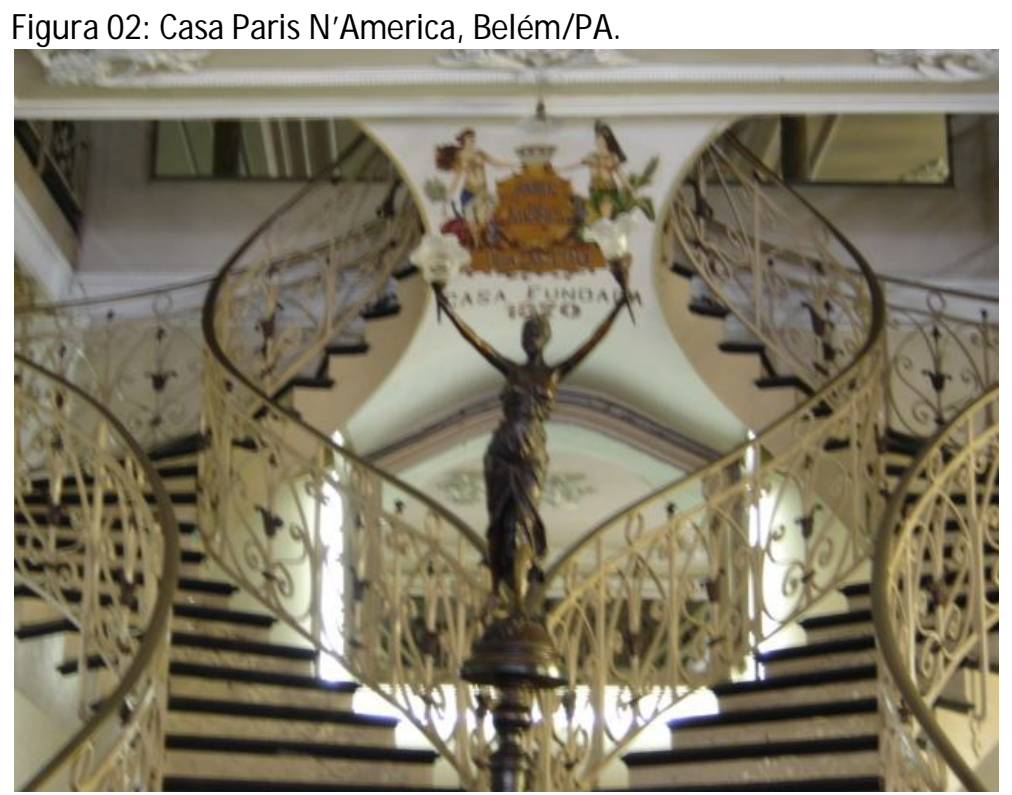

Fonte: Autor, 2005.

O processo de urbanização e industrialização brasileira ocorrido a partir da era Vargas, proporcionou algumas transformações nas cidades amazônicas e teve como 
consequência a redução da qualidade do espaço público e da paisagem urbana do período da Belle Époque, em razão da falta de planos urbanísticos adequados. 0 afastamento das cidades dos rios, a marginalização dos cursos d'água e das áreas verdes, a falta de saneamento, a baixa densidade e a expansão desenfreada trouxeram problemas urbanísticos e sociais com os quais convivemos na atualidade. Diante das políticas ambientais de preservação da floresta em contraponto com a falta de infraestrutura das cidades amazônicas, José Alberto Tostes relatou o conflito entre a Amazônia verde e a Amazônia urbana. E de fato, a urbana é agonizante.

Na segunda metade do século XX, o governo do presidente Emílio Médici implantou o Plano Nacional de Integração com o objetivo de ocupar a Amazônia. Uma nova onda migratória na Amazônia ofereceu terras para a produção agrícola e pecuária. A floresta era vista como uma barreira para o desenvolvimento e para a integração regional e não como uma fonte de recursos para o Brasil. Assim como os seringueiros da Belle Époque e os soldados da borracha do SEM TA no governo Getúlio Vargas, essa terceira invasão intensificou os problemas urbanos e sociais nas cidades amazônicas.

É importante iniciarmos a reflexão com essa breve introdução sobre o processo histórico da ocupação do território para embasarmos as particularidades da arquitetura da contemporaneidade nas cidades amazônicas. Em meio século foi desmatado $18 \%$ da floresta, área compatível com a França, em ocupações realizadas pela pecuária extensiva, exploração inadequada da madeira e implantação de assentamentos urbanos e rurais em área de preservação.

\section{ARQUITETURA CONTEM PORÂNEA}

Para falarmos sobre a arquitetura na Amazônia, precisamos olhar também para o que ocorre no continente e também na produção mundial. No mundo globalizado há cada vez mais acesso as informações e produtos que interferem na produção local. Há uma busca pela padronização nas legislações vigentes. Benéfica para a produção industrial e prejudicial ao comportamento humano. Ser "moderno" é também acessar os bens de consumo e nivelar a informação e as tecnologias em distintas regiões. A globalização desnivela a participação do produtor local, que, em uma primeira análise, prejudica as relações locais, mas representa uma oportunidade para estar no contexto. Estar no contexto pode significar o rompimento com as tradições locais. As campanhas publicitárias são estrategicamente estudadas para influenciar o comportamento da sociedade e balizar o consumo. Quanto mais homogêneo, melhor. Em um continente com tamanha diversidade cultural e miscigenação a homogeneização do comportamento é um atentado as diferentes culturas. 
Figura 03: SEINF- M acapá/AP. Vilanova Artigas,1970.

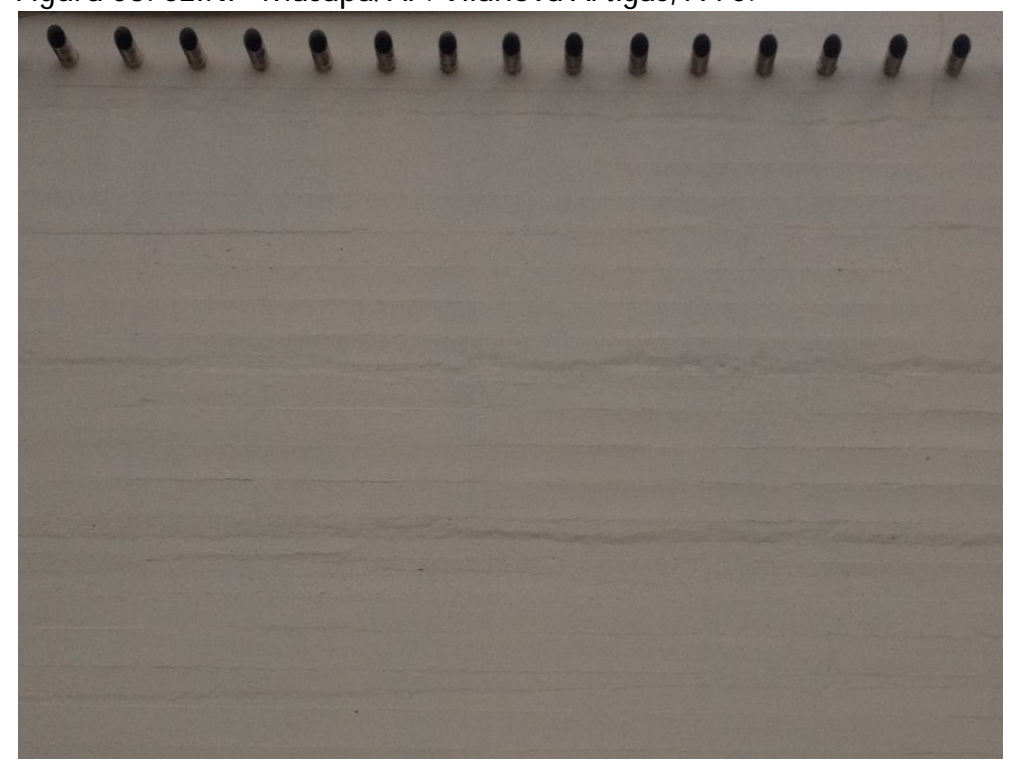

Fonte: Autor, 2015.

Na Arquitetura não é diferente. Esse fenômeno ocorre pelo "canto da sereia" da arquitetura excepcional que invadem os sites e as revistas especializadas e causam uma perigosa sedução aos estudantes e arquitetos. A arquitetura excepcional ou excêntrica tem mais destaque na mídia especializada do que a arquitetura do cotidiano ou de tecido. A arquitetura moderna possibilitou através do modus operandi, atender as novas exigências da sociedade para ocupação do meio urbano, com construções dotadas de novos requisitos provenientes dos avanços da sociedade industrial e possibilitou o debate entre a tradição e a modernidade. A arquitetura do cotidiano ou de tecido é aquela produzida pela grande maioria dos arquitetos que não se caracteriza pelos edifícios excepcionais de uma cidade. Essas arquiteturas de tecido nos anos 50 e 60 no Brasil possuem atemporalidade e qualidade. Edifícios menos pretensiosos do ponto de vista formal e de hierarquia e mais incorporados ao tecido urbano. Os bairros do Leblon no Rio de Janeiro, Higienópolis em São Paulo e Moinhos de Vento em Porto Alegre são exemplos dessa produção.

Helio Piñón relatou 0 abandono dos princípios da modernidade no ensino de arquitetura na atualidade. A materialidade tem mais valor do que a concepção? A obra concluída é mais importante do que o projeto? A sociedade da era digital em que vivemos representa uma crise de autenticidade como descreveu Fernando Diez, inerente aos novos processos que modificam significados e valores na arquitetura. A mercantilização da arquitetura é outro fenômeno da contemporaneidade, conforme escreveu Edson Mahfuz. Há um excesso de produção e exposição de baixa qualidade onde o sucesso profissional está desvinculado da qualidade. Os edifícios são "objetos de consumo" onde a pauta é a "moda ou a tendência". 0 arquiteto cada vez mais se afasta do papel de artesão de edifícios para tornar-se um homem de negócios. 
0 fácil acesso proporcionado pela internet aos novos materiais, tecnologias, conhecimentos e culturas possibilitam novas reflexões sobre a produção arquitetônica. A interpretação indevida pode prejudicar a produção local e a qualidade arquitetônica. A falta de recursos e de mão de obra especializada podem produzir dificuldades na execução e efeitos nefastos no resultado final. A polaridade entre a universalidade $x$ regionalidade não representa uma oposição entre o que é global e o que é local. Não há muros. Por mais que existam diretrizes comuns, haverá produções distintas devido aos recursos disponíveis, fatores culturais, econômicos e da Geografia. A relação entre o macro e o micro é determinada por uma série de fatores inerentes a disciplina e também a fatores exóticos a Arquitetura. Os fatores exóticos da disciplina não servirão de objeto de análise desse ensaio que também interferem e poderiam contribuir com o assunto. Não é o nosso tema. A cultura disciplinar do Arquiteto é a forma como interferimos na sociedade, independente da escala, seja nas cidades ou nos edifícios, através de projetos e teorias. Nessa ótica, fica mais evidente que não podemos generalizar a Arquitetura na Amazônia como única, tendo em vista a extensão territorial da Floresta Amazônica que rompe as fronteiras do Brasil, Bolívia, Colômbia, Equador, Guiana Francesa, Guiana, Peru, Suriname e Venezuela.

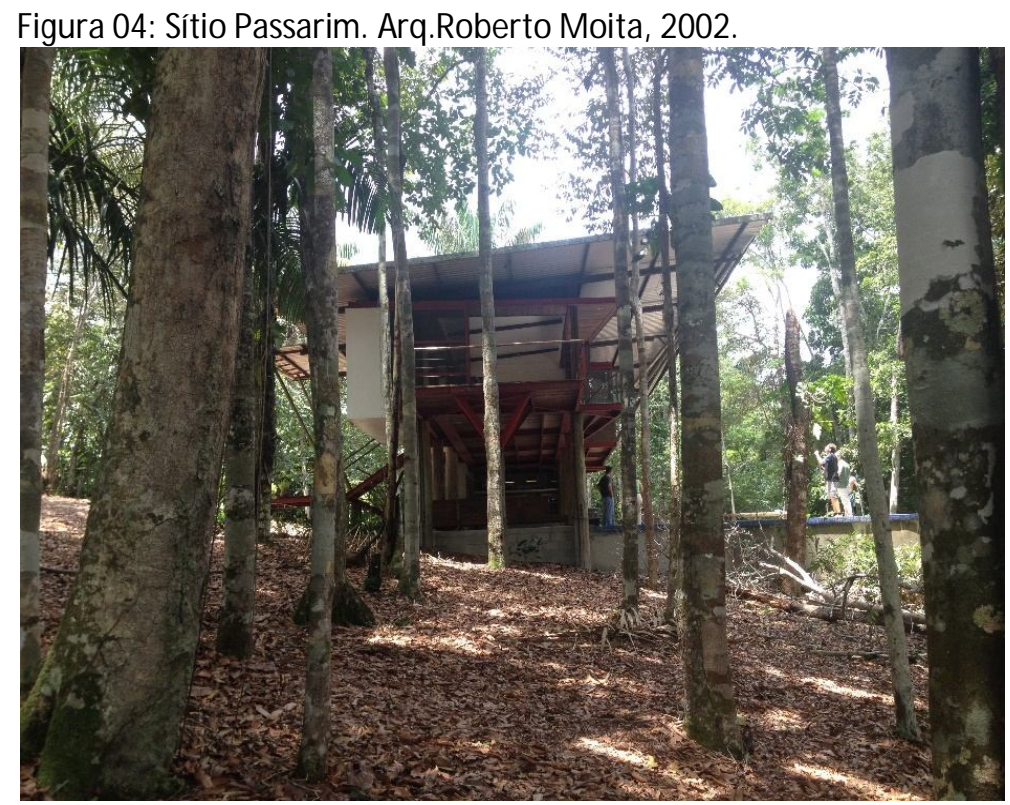

Fonte: Autor, 2016.

Nunca se construiu tanto como no século XX. 0 crescimento e o desenvolvimento das cidades americanas, asiáticas e africanas contribuíram para novas experimentações, frente a Europa devastada pelas Guerras. A contestação à Arquitetura M oderna acentuou no Brasil no período pós-Brasília e foi apimentada pela crítica de Max Bill, e pelas publicações de Jane Jacobs, Denise Scott-Brown e Aldo Rossi. Utilizar exemplares referenciais, observar a sua relação com a história, técnicas construtivas e cultura, identificar valores presentes nas relações intrínsecas do projeto a relação com a esca- 
la da cidade foram alguns pontos criticados da arquitetura moderna, embora contestados. Le Corbusier descreveu em Por uma Arquitetura em 1923, a importância da história da Arquitetura. Mies Van der Rohe demonstrou a sua preocupação com 0 entorno conforme comprovou recentemente os textos de Cristina Gastón. Segundo Helio Piñón, o projeto de arquitetura ao longo da história teve apenas dois sistemas formais completos: o classicismo (até o início do século XX) e a arquitetura moderna. Pós-modernismo, Minimalismo, Desconstrutivismo, Estruturalismo, PósEstruturalismo, High-Tech, Contextualismo, Brutalismo e outros "ismos" não representaram uma mudança no sistema formal, apenas nuances de modernidade. Continuamos modernos.

\section{MODERNO POR NATUREZA}

A madeira é um importante elemento na história da arquitetura brasileira. Enquanto material de revestimento ou técnica construtiva, sempre foi um recurso amplamente utilizado pelos construtores no Brasil. No período colonial, os alemães trouxeram a técnica do enxaimel para o Vale do Itajaí. Os portugueses trouxeram a técnica da taipa e implantaram o muxarabi, utilizado pelos árabes como elemento formal, simbólico, comportamental e climático nos edifícios. As "misteriosas" treliças de madeira foram desprestigiadas pela Corte Real na ocasião da mudança para o Brasil em 1808, mas permaneceram como importante elemento de proteção das fachadas.

Figura 05: Residência Schuster. Severiano Porto, 1978.

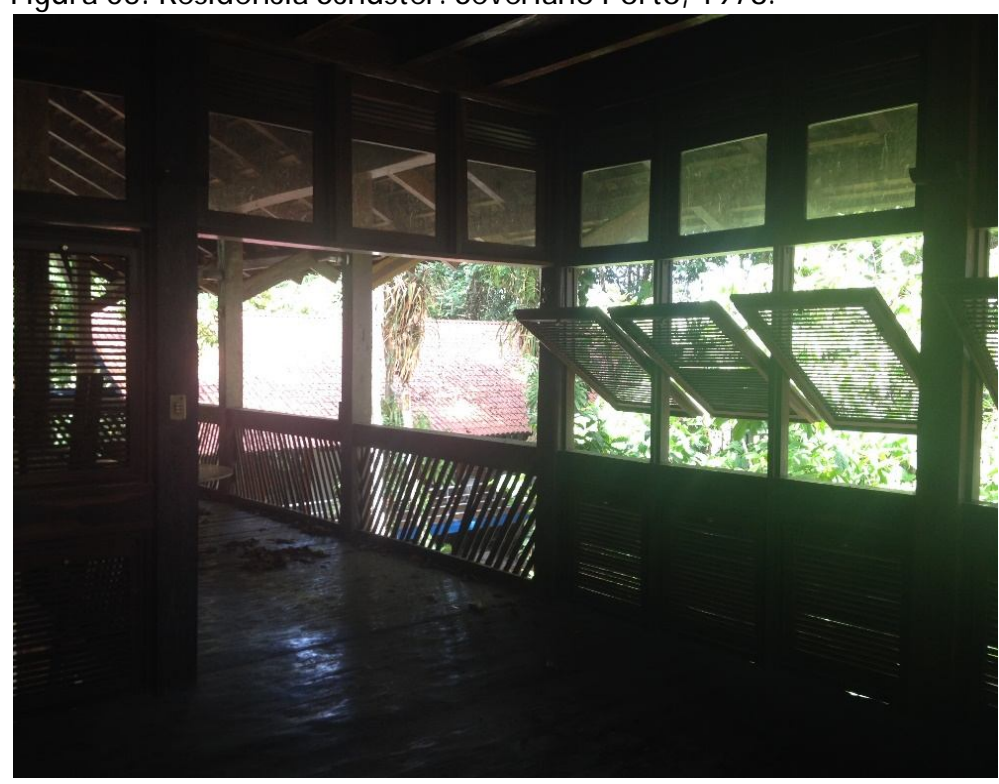

Fonte: Autor, 2016.

No início do século XX, o concreto armado possibilitou uma mudança estética e estrutural na organização das partes do edifício. A estrutura livre liberou a comparti- 
mentação. Enquanto Auguste Perret e Le Corbusier utilizaram o concreto armado como elemento formal e construtivo na modernidade francesa, outras experiências ocorriam na Europa, Ásia e Estados Unidos com a pedra, o aço e a madeira. 0 conceito da modernidade não estava relacionado a um único material ou técnica construtiva, mas a independência e flexibilidade entre a estrutura portante e a vedação do edifício.

A utilização da madeira na arquitetura moderna brasileira está relacionada ao debate entre o clássico e o pitoresco. Enquanto o concreto armado representava a inovação tecnológica, o "clássico" e a permanência, a madeira expressava o pitoresco, 0 transitório, o bucólico e a tradição. A modernidade brasileira transgrediu essa distinção e possibilitou transitar por diferentes materiais e técnicas construtivas. 0 edifico "se vestia" conforme o caráter e o lugar: com concreto armado nos grandes centros urbanos, em razão da disponibilidade de materiais para os agregados e mão de obra capacitada e a madeira no "Brasil de dentro" com material abundante e uma mão de obra qualificada. Hugo Segawa relatou sobre as outras modernidades no Brasil e demonstrou que além das modernidades das escolas carioca e paulista, houveram outras produções com características singulares. A modernidade amazônica é ainda um tema aberto e frutífero.

Em 1929, durante a primeira expedição de Le Corbusier a América do Sul, o arquiteto franco-suíço desenvolveu o projeto para o embaixador chileno em Buenos Aires, Matias Errázuriz Ortúzar, para uma casa de veraneio em Zapalar no Chile. 0 projeto não foi construído, mas incluiu a madeira como técnica construtiva da modernidade. Em 1933, Gilberto Freyre publicou "Casa-Grande \& Senzala" e apontou para a necessidade de observar as técnicas primitivas e para o lugar. A adaptação às chuvas torrenciais e ao sol excessivo nos trópicos possibilitou aos portugueses a utilização de paredes grossas de taipa e telhados com beirais avantajados, que não eram utilizados pela arquitetura portuguesa. Richard Neutra publicou "Architecture of social concern in regions of mild climate" em 1948 e visitou diversas cidades brasileiras em razão dos Acordos de Washington quando o Brasil se uniu aos Aliados na Segunda Guerra Mundial. Esse livro influenciou diretamente a arquitetura de Oswaldo Bratke e Severiano Porto.

Lucio Costa buscou a identidade da arquitetura brasileira no período colonial e barroco, porém atenta a vanguarda corbusiana. 0 modernismo representou mais do que a emergência da nova arquitetura, mas o espírito da industrialização, urbanização e construção de uma identidade nacional. Em 1934, ao avançar na modernidade, participou do concurso para projetos da vila operária em Monlevade, com uma série de edificações com diferentes usos que compunham um conjunto arquitetônico que não foi construído. As unidades habitacionais na encosta dos morros do sítio na periferia do conjunto apresentavam a união entre a técnica primitiva e a contemporânea: concreto armado e pau-a-pique. 


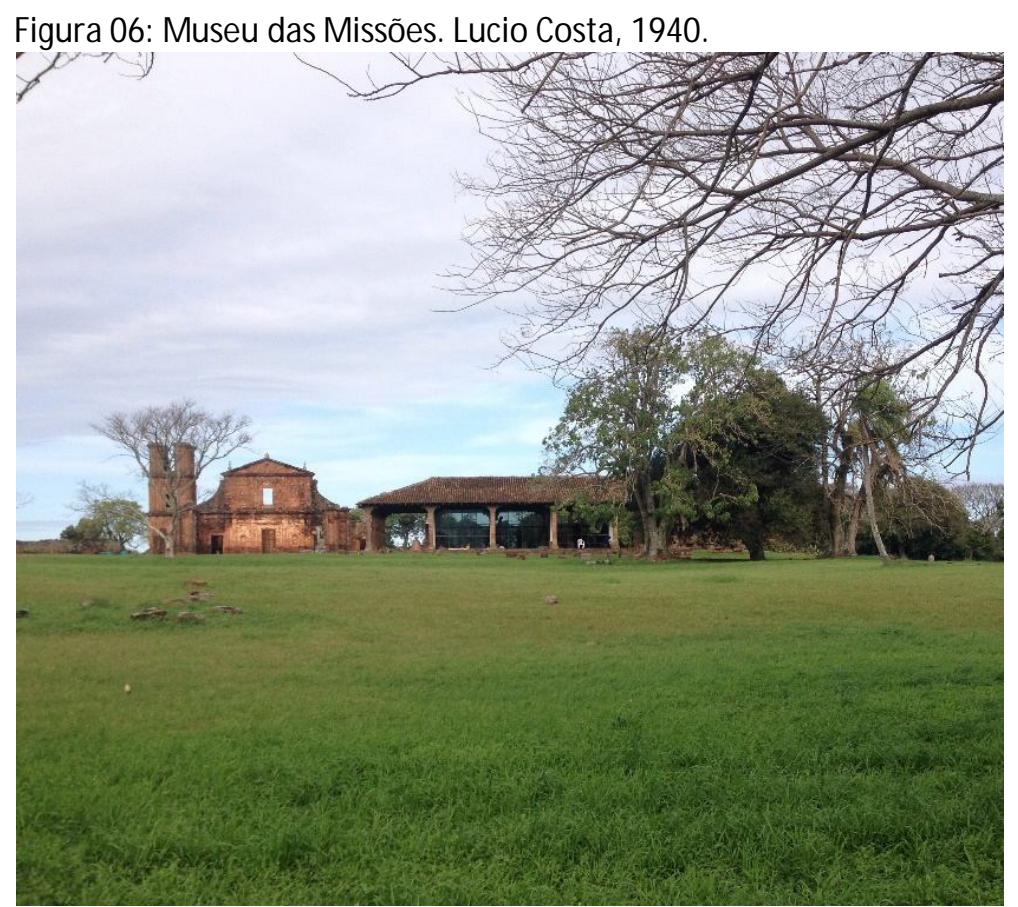

Fonte: Autor, 2015.

A unidade habitacional era elevada por pilares em concreto armado (pilotis) e também paredes em pedra para conter a encosta, o volume da residência era vedado com paredes de taipa, com a técnica construtiva presente nas construções da região. Em 1938, Lucio Costa foi convidado por Rodrigo Melo Franco de Andrade para dirigir uma nova autarquia - o IPHAN - Instituto de Patrimônio Histórico e Artístico Nacional, e em uma das suas primeiras atividades, conheceu e registrou as M issões Jesuíticas nas terras do presidente Getúlio Vargas, natural de São Gabriel no Rio Grande do Sul. Ao verificar as condições das ruínas dos 7 povos das M issões (São Gabriel, Santo Ângelo, São Nicolau, São Luiz Gonzaga, São M iguel Arcanjo, São Lourenço e São João Batista), identificou em São Miguel, uma igreja em pedra, que resistiu aos diversos combates e ao tempo. No projeto do abrigo para as peças artísticas encontradas nas cercanias do templo, utilizou a madeira como estrutura do telhado no museu e também nas esquadrias e na estrutura da varanda da casa do Zelador. Le Corbusier projetou a cobertura em madeira exposta na residência chilena, mas Lucio Costa observou as técnicas construtivas e tipologias utilizadas pelos Guaranis e projetou o M useu das $M$ issões em contraponto com a qualidade espacial do museu com a transparência e 0 enquadramento. Tradição e modernidade.

Em 1944, Lucio Costa foi contratado pela família Guinle para a construção de uma pousada para os proprietários e interessados em lotes no Parque São Clemente em Nova Friburgo. 0 Park Hotel, com dez apartamentos na parte superior permite 0 ingresso através do pilotis com toras de eucalipto em um lobby bem articulado com 0 restaurante e a sala de jogos com vista orientada para os jardins de Glaziou no atual Country Club. Em posição mais estratégica, a parte administrativa e dos serviços da 
pousada em alvenaria. A utilização da madeira no Park Hotel não ocorreu somente nas esquadrias e na cobertura como ocorreu na casa do Zelador e no M useu nas M issões no Rio Grande do Sul, mas na estrutura independente de parte do edifício em diálogo com paredes portantes em pedra e alvenaria. Independente da região, materiais ou técnicas construtivas era possível realizar arquitetura moderna no "Brasil de dentro", em locais mais distantes, com a mesma qualidade. A arquitetura moderna não dependia dos materiais nem de uma mão de obra definida.

0 arquiteto Álvaro Vital Brazil foi um dos primeiros peregrinos, conforme descreveu Hugo Segawa, a levar a modernidade para o interior do Brasil. Em 1943, foi convidado para chefiar o Departamento Engenharia do SEM TA e projetou os abrigos para os "soldados da borracha", incentivado pela assinatura dos Acordos de Washington. Com o impedimento nazista da via marítima, era necessário deslocar os trabalhadores em caminhões do interior do nordeste brasileiro até a cidade de Belém, por onde seriam deslocados pelo Rio Amazonas aos seringais. Para realizar esse deslocamento foi necessário construir os "pousos" em pontos estratégicos para os trabalhadores descansarem antes de seguirem para a próxima etapa da viagem. A construção dos alojamentos foi realizada com brevidade pela urgência do acesso à borracha pelos Aliados e a necessidade de descanso aos trabalhadores no deslocamento de leste para oeste do país. Vital Brazil, observou à disponibilidade dos recursos humanos e os materiais existentes nos locais para evitar problemas logísticos. Incorporou a "rede", mobiliário que havia sido citado por Mário de Andrade em "Macunaíma", como gerador do espaço interno e modulou a estrutura em madeira em pilotis e incorporou esse modo do interior brasileiro em uma construção moderna por concepção. 0 módulo de $3 \times 3$ metros é ideal para a utilização do mobiliário e também para a técnica construtiva com vãos que permitiam a construção em madeira rústica e sem tratamento de serraria e a cobertura em palha de babaçu, carnaúba ou buriti. A construção em grande parte era em pilotis Além dos pousos, Vital Brazil realizou os projetos da Base Aérea de M anaus (1944) e do aeroporto de Belém (1945) onde incorporou a madeira como elemento estrutural e de revestimento.

As experiências bucólicas com a madeira iriam se intensificar com a construção das casas de final de semana no sudeste brasileiro. Enquanto nas grandes cidades o concreto armado era a pauta nas construções das residências, a madeira, a pedra e os materiais locais definiam a modernidade nas cidades do interior. 0 russo Gregori Warchavchik, projetou em 1946, o pavilhão da casa de Marjore Prado no Guarujá em São Paulo. 0 pavilhão circular com estrutura em madeira e coberto em Sapê explorava a rusticidade do material no ambiente praiano. Carlos Ferreira construiu a sua casa em Nova Friburgo em 1949 e utilizou estrutura em madeira, pau a pique e pedra. Francisco Bolonha projetou a residência do embaixador Hildebrando Accioly em Petrópolis em 1949-50. Oscar Niemeyer construiu em Mendes em 1949 uma casa de final de semana com uma treliça em madeira junto à fachada inclinada. Le Corbusier, construiu Le Cabanon em Cap.Martin em 1951. O pavilhão Lowndes na Fazenda Sa- 
mambaia em Petrópolis em 1953-54 dos Irmãos Roberto foi construído com estrutura em madeira e pedra. Assim como os Irmãos Roberto, Henrique M indlin desenvolveu na fazenda Samambaia a Residência Souza Carvalho em 1955. A construção da nova capital brasileira apresentou em construções temporárias a utilização da madeira. 0 "Catetinho", projeto de Oscar Niemeyer em 1955, foi a primeira residência oficial de Juscelino Kubitschek e projetada para uma execução em curto espaço de tempo e com poucos recursos.

A experiência de Oswaldo Bratke na construção da Vila Serra do Navio e Vila Amazônia em Santana em 1955, representou a materialização do ideal modernista no interior da selva amazônica. As grandes dificuldades impostas pelo isolamento e logística na região foram motivação para Bratke no desenvolvimento do projeto para a mineradora ICOM I para extração do manganês no então Território Federal do Amapá. A imersão na região e o entendimento das condições do lugar e da disponibilidade de recursos humanos e de materiais foram fundamentais para o desenvolvimento do projeto que inovou com o desenvolvimento em todas as escalas: do desenho do mobiliário até a infraestrutura. Foi necessário para garantir a qualidade em todas as escalas das vilas. Projetos de urbanização, distribuição de água e luz, instalações de rede de incêndio, esgoto, águas pluviais, a construção de casas para operários e para empregados categorizados, chefes de serviços, mobiliários, máquinas e prédios de interesse coletivo. Enquanto a Vila Serra do Navio exigiu um núcleo autosuficiente que foi interligado por linha férrea ao Porto de Santana, onde ficava a Vila Amazonas próxima de Macapá, para escoamento da produção do Manganês via marítima. A experiência de Oswaldo Bratke na Amazônia demonstrou que a modernidade era possível no "Brasil de dentro".

Figura 07: Igreja. Oswaldo Bratke, 1956.

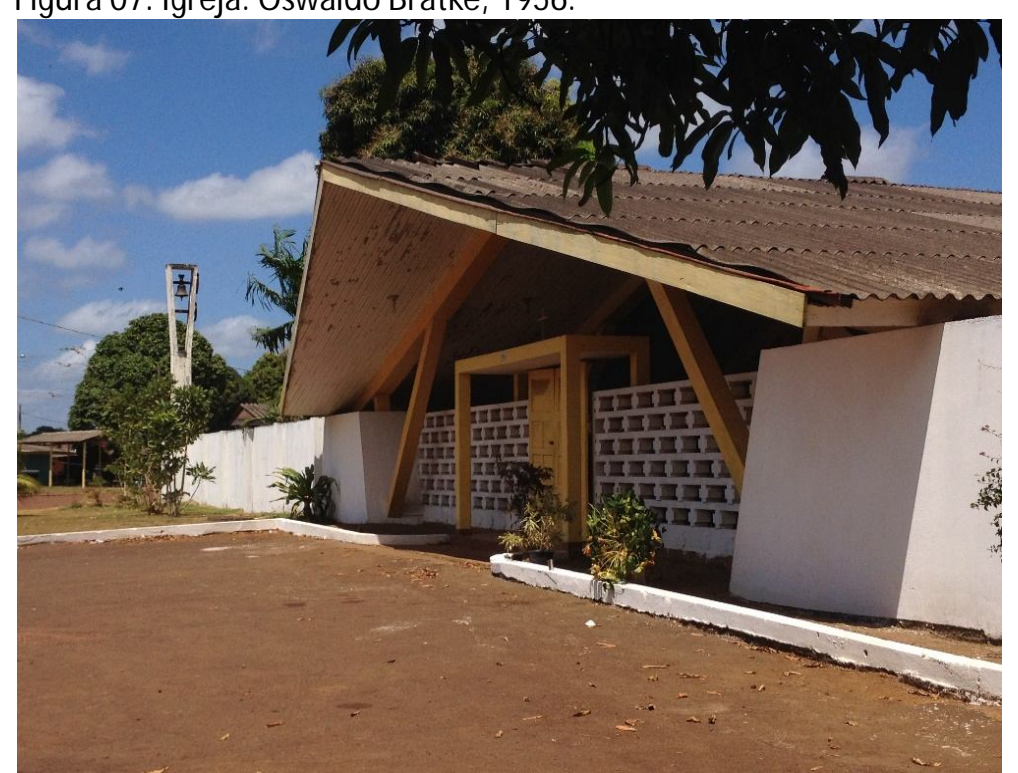

Fonte: Autor, 2015. 
Os precedentes da arquitetura moderna na Amazônia demonstram a influência dos cânones da primeira fase da arquitetura moderna brasileira. Lucio Costa e Oscar Niemeyer, como fonte inspiradora. Oswaldo Bratke e Álvaro Vital Brazil, os pioneiros na região amazônica. Outros arquitetos, de forma pontual, participaram com projetos na região. Paulo Antunes Ribeiro fez Hotel Amazônia em 1947 com jardins de Burle Marx. Após a construção de Brasília, o processo de integração da região amazônica ao território foi intensificado e obras institucionais e de infraestrutura surgiram nas principais cidades da região. Em Cuiabá, no final dos anos 50 o paulista Oscar Arine, 0 carioca Donato Mello Junior e o mineiro João Timotheo da Costa foram os precursores do modernismo no estado. Em Belém, o engenheiro-arquiteto paraense Camilo Porto de Oliveira com os gaúchos Jorge Derenji e Jussara Derenji iniciaram o primeiro curso de Arquitetura na Amazônia em 1964 e junto com o acreano M ilton Monte foram os pioneiros do modernismo no Pará. Com o Golpe Militar em 1964, a Amazônia passou a ser tratada como segurança nacional e o processo de ocupação foi acentuado. A missão cultural promovida pelo Governador Artur Reis contratou arquitetos e engenheiros do Rio de Janeiro para atender as necessidades de projetos em infraestrutura para o estado do Amazonas. Sergio Bernardes desenvolveu um projeto para 0 Hotel Tropical em Manaus não executado. Vilanova Artigas projetou alguns edifícios públicos em Macapá no final da década de 60. Ricardo Lefèvre projetou o Aeroporto Eduardo Gomes em Manaus no início dos anos 70.

Seja no Park Hotel em Nova Friburgo, no "Catetinho" em Brasília ou na Vila Serra do Navio no Amapá, a tradição da madeira como técnica construtiva, material e elemento estrutural foi incorporada ao modus operandi da arquitetura moderna brasileira. Moderno por natureza.

\section{SEVERIANO MARIO PORTO, ARQUITETO MODERNO}

Severiano Mário de Magalhães Porto nasceu em 19 de fevereiro de 1930 na cidade de Uberlândia em M inas Gerais. Formado pela Faculdade Nacional de Arquitetura da Universidade do Brasil em 1955, trabalhou na Construtora Ary C.R.de Britto como Diretor Técnico e realizou projetos nos estados do Rio de Janeiro e em M inas Gerais. Iniciou a sua trajetória na Amazônia em 1965, quando foi convidado pelo interventor do estado do Amazonas Artur Reis para fazer o projeto do Anexo do Palácio Rio Negro, a residência oficial do Estado, o estádio Vivaldo Lima e a sede da Assembleia Legislativa. "M ineiro de nascimento, carioca por formação e amazonense de coração" foi o seu "cartão de visitas" como representante de uma geração de arquitetos peregrinos, que levaram a arquitetura para os mais distantes pontos do país após a construção de Brasília. 0 deslocamento dos profissionais do eixo Rio-São Paulo para o interior do Brasil em razão das novas demandas surgidas pelo programa de ocupação do território proporcionou a chegada dos arquitetos ao restante do país. A nova geração de arquitetos era peregrina e estavam também na periferia do eixo Rio-São 
Paulo. De Minas Gerais ao Rio Grande do Sul, da Amazônia e Pantanal ao Nordeste, esses arquitetos auxiliaram na construção de um novo país que não ocupava mais somente a faixa litorânea. Era o Brasil que José Bonifácio idealizou ainda no século XIX com a interiorização da capital federal. Além da arquitetura produzida, novas escolas de arquitetura surgiram em todas as regiões brasileiras com os alicerces das escolas carioca e paulista, porém com um "tempero" diferente. A Revista Projeto teve um papel fundamental na divulgação da arquitetura brasileira principalmente na década de 80, como um veículo que divulgou a produção do território brasileiro e elevou Severiano Porto a um status de ícone da diversidade da produção brasileira.

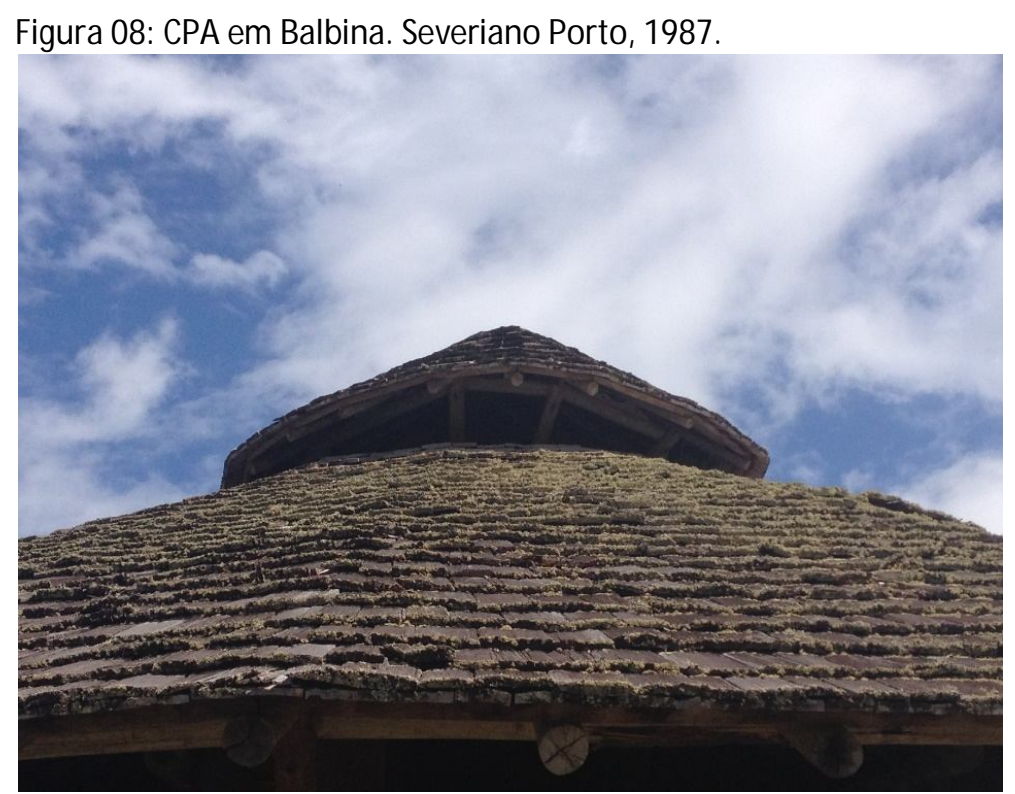

Fonte: Autor, 2016.

A premiação na Bienal de Buenos Aires em 1985 foi um marco na carreira internacional do arquiteto. Em 1987, foi considerado o arquiteto do ano pela revista francesa L'Architecture d'Aujourd'hui. Se a década de 80 proporcionou o destaque internacional, 0 arquiteto recebeu diversas premiações pelo Instituto de Arquitetos do Brasil com suas obras desde 1965. Estádio Vivaldo Lima, Restaurante Chapéu de Palha, Edifício-sede da SUFRAMA, Reservatórios da COSAMA, Residência do Arquiteto, Residência Schuster, Pousada de Silves, CPA em Balbina e Campus da Universidade do Amazonas (atual UFAM) foram destacadas e representavam um discurso distinto ao praticado no eixo Rio-São Paulo. Por várias vezes contestada no epicentro da arquitetura brasileira, a sua obra imprimia o debate entre o regionalismo e as soluções universais, entre a tradição e a modernidade. 0 regionalismo, muitas vezes utilizado como termo pejorativo e reduzido pela materialidade e não pelo todo. Por outro lado, após várias premiações e o reconhecimento internacional nos anos 80 , um "rótulo" de arquiteto da madeira que não agradava ao arquiteto e de certa forma, simbolizava a busca por heróis e caminhos para a arquitetura após o surgimento do SAL - Semi- 
nário de Arquitetura Latino-americana em 1985. Assim foi para Severiano Porto com a madeira, Oscar Niemeyer com o Concreto Armado, Rogelio Salmona e Eládio Dieste com o tijolo.

Colocou a Amazônia através das suas obras no mapa da arquitetura latinoamericana, com edifícios importantes e referenciais. A capacidade de adaptar o edifício a diversas situações e condições, ora com o concreto armado, com o aço, com a cerâmica armada e com a madeira conforme a necessidade e o caráter a ser empregado, porém com a mesma modernidade e qualidade. Permite afirmar que 0 arquiteto foi um experimentalista e não somente o "Arquiteto da Madeira", embora trabaIhasse com o esse material com enorme desenvoltura. "Moderno por Natureza", Severiano Porto foi um líder no desenvolvimento urbano e na consolidação do território na região Amazônica e participou ativamente do cenário político e social da implantação da Zona Franca de Manaus no final da década de 60. Autor de mais de 300 projetos e de obras em 11 estados brasileiros, foi referência na formação dos arquitetos latino-americanos nas décadas de 80 e 90 . As principais obras são o Centro de Proteção Ambiental em Balbina, o edifício-sede da SUFRAM A e o campus da Universidade Federal do Amazonas onde utilizou madeira, concreto armado e aço. Recebeu diversas condecorações pela sua obra e atividade profissional e atualmente encontra-se internado em uma clínica em estágio avançado do Alzheimer.

Uma parte significativa das obras premiadas foram demolidas ou encontram-se em estágio avançado de desconfiguração. 0 estádio Vivaldo Lima, projeto premiado pelo Instituto de Arquitetos do Brasil em 1965, foi demolido para a realização da Copa do Mundo em Manaus. É um exemplo da fragilidade do patrimônio moderno diante das novas necessidades. O CPA de Balbina encontra-se em avançado estado de abandono e corre risco de desabar. Durante o I SAM A - Seminário de Arquitetura Moderna na Amazônia que ocorreu em fevereiro de 2016 em Manaus, foi redigida a "Carta aberta do I SAM A" e iniciada uma campanha \#salvevilabalbina para recuperar a principal obra de Severiano Porto. A Assembleia Legislativa do Estado do Amazonas em conjunto com o CAU-AM iniciou em 2015 o processo de tombamento de 29 obras do arquiteto no estado. Em 18 de fevereiro de 2016 foram tombadas pelo estado e representam uma possibilidade para a preservação e recuperação dos edifícios.

De forma poética poderíamos fazer uma analogia sobre a distinção da utilização do espaço territorial pelos europeus e pelos indígenas ao concreto armado e a madeira: em relação ao modelo de ocupação, apropriação e exploração da terra dos europeus a permanência da estrutura em concreto armado, enquanto a tradição indígena de pertencimento ao meio e não da apropriação para a transitoriedade das estruturas em madeira. Severiano Porto trabalhava com esse conceito nas obras distantes do meio urbano em que utilizava a madeira como elemento estrutural e construtivo. Como preservar edificações biodegradáveis em razão dessa analogia? Elas não se apropriam, pertencem. Talvez um caminho seja olhar para o oriente e aprender com 
as reconstruções dos templos para manutenção da técnica construtiva e substituição das peças em decomposição. 0 projeto permanece.

Atualmente, há um ostracismo nas escolas de arquitetura brasileiras em relação a Severiano Porto, seja pela falta de publicações ou simplesmente pelo desinteresse por esse importante arquiteto. Curiosamente, esse fenômeno ocorre também nas escolas de Arquitetura e Urbanismo da Amazônia. 0 arquiteto da Amazônia, como ficou conhecido internacionalmente, nos deixou uma vasta quantidade de obras com uma arquitetura responsável e criteriosa. Entre as suas lições a consideração pelos mestres modernos, um olhar atento para a cultura caboca, a atenção ao lugar e um profundo conhecimento do canteiro de obras. É importante observar que o uso da madeira foi praticado desde a arquitetura colonial brasileira e o modernismo incorporou essa tradição. Severiano Porto não foi o primeiro a utilizar a madeira, mas juntamente com Zanine Caldas são referenciais na arquitetura brasileira. Severiano Porto utilizou a madeira com maestria e produziu uma arquitetura moderna na Amazônia, diante dos recursos disponíveis da sua época. Atualmente há grandes dificuldades para a permanência das suas obras em razão das características biodegradáveis dos materiais, pela manutenção inadequada e principalmente pela perda da mão de obra habilitada e qualificada para trabalhar com as técnicas primitivas. A globalização da arquitetura na Amazônia reduziu as demandas pelas técnicas primitivas que estão sendo gradativamente perdidas. Para recuperar e preservar a obra de Severiano Porto é preciso reaprender as técnicas rudimentares na Amazônia e ensiná-las aos arquitetos, engenheiros e carpinteiros.

Severiano não é mineiro, carioca ou amazonense: é brasileiro.

\section{BIBLIOGRAFIA}

বttp://www.seminario2016.docomomo.org.br/artigos_apresentacao/sessa0\%2018/ DOCO_PE_S16_CERETO_SANTOS_ESPINOSA.pdf>.

ABA - Revista Arquitetura Brasileira do Ano/ Rio de Janeiro, GB - 1967/68. 216p.

CASTOR, Ricardo Silveira. Modernidade e primitivismo na arquitetura de Mato Grosso. Confrontos da segunda metade do século 20. Arquitextos, São Paulo, ano 11, n.126.05,Vitruvius,nov.2010.

CERETO, M arcos. Amazônia moderna. A criação do Seminário de Arquitetura M oderna na Amazônia - SAM A. Drops, São Paulo, ano 17, n. 102.01, Vitruvius, mar. 2016.

CERETO, Marcos; SANTOS, Luiza; Espinosa, Vasilka. Recife 1762 e 1435: considerações sobre a permanência e o transitório na obra de Severiano Porto. XI Docomomo Brasil, 2016.

COMAS, Carlos Eduardo Dias. Lucio Costa e a revolução na arquitetura brasileira 30/ 39. e lenda(s e) Le Corbusier. Arquitextos, São Paulo, ano 02, n. 022.01, Vitruvius, mar. 2002.

CONDURU, Roberto.Vital Brazil.São Paulo: Cosac \& Naify Edições, 2000. 
COSTA, Lucio. Lucio Costa: registro de uma vivência. São Paulo, Empresa das Artes,1995.

DIEZ, Fernando. Crisis de autenticidad - Cambios en los modos de producción de la arquitectura argentina. Buenos Aires: Summa+Libros, 2008.

FREYRE, Gilberto. Casa-grande \& senzala. Formação da família brasileira sob o regime da economia patriarcal. 51a Edição. São Paulo: Global, 2006.

MAHFUZ, Edson. 0 sentido da arquitetura moderna brasileira. Arquitextos, São Paulo, ano 02, n. 020.01, Vitruvius, jan. 2002.

MINDLIN, Henrique. Gilberto Freyre e os arquitetos. Revista IAB-Guanabara. Número 4. Janeiro/Fevereiro de 1962. P.7-12.

NEVES, Eduardo Góes. Arqueologia da Amazônia. Rio de Janeiro: Jorge Zahar, 2006, 86 páginas.

PIÑÓN, Hélio. Teoria do Projeto.Traduzido por Edson Mahfuz. Porto Alegre: Livraria do Arquiteto, 2006.

PORTO, Severiano. Depoimento. [12 de maio, 2002]. Rio de Janeiro. Entrevista concedida a Marcos Cereto.

SEGAWA, H.; DOURADO, G. M. Oswaldo Arthur Bratke. A arte de bem projetar e construir. 2. ed. São Paulo: PW Editores, 2012.

SEGAWA, Hugo. Arquiteturas no Brasil 1900-1990. 2. ed. São Paulo: Editora da USP, 1999.

TOSTES, Jose Alberto. Amazônia verde versus Amazônia Urbana: a visão do estelionato urbano. Site do CAU-BR. Out. 2013 «ttp://www.caupr.org.br/?p=7781>.

VENTURI, Robert; IZENOUR, Steven; BROWN, Denise. Aprendiendo de Las Vegas. Barcelona: Gustavo Gili, 1978.

VIDAL, Celma Chaves de Souza Pont. Arquitetura, modernização e política entre 1930 e 1945 na cidade de Belém. Arquitextos, São Paulo, ano 08, n. 094.06, Vitruvius, mar. 2008.

Artigo recebido em 14 de julho de 2016.

Aprovado em 18 de julho de 2016. 